\title{
PERAMALAN PERMINTAAN SUKU CADANG OTOMOTIF KARET DENGAN INTEGRASI AGENT BASED MODELLING DAN DOUBLE EXPONENTIAL SMOOTHING
}

\section{FORECASTING RUBBER BASED AUTOMOTIVE DEMAND USING AGENT BASED MODELLING AND DOUBLE EXPONENTIAL SMOOTHING}

\author{
Dewi Auditiya Marizka ${ }^{1}$, Yandra Arkeman ${ }^{2)}$, Sapta Rahardja ${ }^{2)}$, Hartrisari Hardomidjojo ${ }^{2)}$, Ono Suparno ${ }^{2)}$ \\ ${ }^{1)}$ Politeknik STMI Jakarta-Ministry of Industry, Indonesia. \\ *E-mail: iburizkakoe@yahoo.co.id \\ ${ }^{2)}$ Department of Agroindustrial Technology, Faculty of Agricultural Technology, \\ Bogor Agricultural University, Campus IPB Darmaga, Bogor 16680, Indonesia
}

Makalah: Diterima 11 Januari 2020; Diperbaiki 30 Oktober 2020; Disetujui 22 November 2020

\begin{abstract}
The objective of this study was to design an agent model for forecasting demand for rubber-based automotive parts using the Agent Based Modelling and Double Exponential Smoothing (ABMDES) approach. Model design in rubber-based automotive spare parts forecasting using the integration of Agent Based Modelling (ABM) approach and Double Exponential Smoothing (DES) technique was done using agent design approach based on class diagram and definition function for each agent in mathematics models including DES-based forecasting. The ABM design has a structure consisting of an agent ID, an attribute to be calculated by the computer and function/process consisting of a function that has values and voids (unstructured). Combining ABM and DES can guide us to see the forecast accuracy, monitoring the estimation of stock shortage and the excess of stock due to errors in DES forecast. Therefore, the Agent Based Modelling-Double Exponential Smoothing (ABMDES) approach is suitable for modelling the demand of rubber-based automotive parts in business simulation.
\end{abstract}

Keywords: double exponential smoothing, function, SMEs, shortage

\section{ABSTRAK}

Tujuan penelitian ini adalah merancang model agen untuk peramalan permintaan suku cadang otomotif berbasis karet dengan pendekatan Agent Based Modelling and Double Exponential Smoothing (ABMDES). Desain model pada peramalan suku cadang otomotif berbasis karet menggunakan integrasi pendekatan Agent Based Modelling (ABM) dan teknik Double Exponential Smoothing (DES) dilakukan dengan menggunakan pendekatan desain agen berbasis diagram kelas (class diagram) dan definisi function untuk setiap agen dalam bentuk model matematika termasuk di dalamnya peramalan berbasis DES. Desain agen berbasis kelas memiliki struktur yang terdiri atas ID agen, atribut-atribut yang akan dilakukan proses perhitungan dengan komputer, dan function/proses yang terdiri atas function yang memiliki nilai dan void (tidak terstruktur). Mengintegrasikan DES dan ABM dapat memandu untuk melihat perkiraan akurasi peramalan, memantau perkiraan kekurangan persediaan (stock) dan kelebihan stock akibat error pada peramalan DES. Oleh karena itu, pendekatan Agent Based Modelling Double Exponential Smoothing (ABMDES) sesuai untuk memodelkan permintaan suku cadang otomotif berbasis karet dalam simulasi bisnis.

Kata kunci: agent based modelling, double exponential smoothing, IKM, function, shortage

\section{PENDAHULUAN}

Perencanaan permintaan dan produksi yang optimal perlu dilakukan oleh industri kecil dan menengah (IKM). Perencanaan permintaan atau peramalan adalah perhitungan yang objektif menggunakan data-data masa lalu untuk menentukan permintaan di waktu yang akan datang (Sumayang, 2003). Penentuan jumlah produk yang seharusnya diproduksi oleh perusahaan dapat dibanntu dengan peramalan permintaan produk. Metode yang digunakan dalam peramalan bertujuan unntuk meminimumkan kesalahan dan agar hasil peramalan mendekati kondisi aktual. Metode peramalan yang digunakan disesuaikan dengan kebutuhan dan jenis peramalan yang akan dilakukan (Wu et al., 2016).
Peramalan permintaan merupakan upaya untuk mengurangi kemungkinan terjadi masalah antara keadaan yang benar-benar akan terjadi di masa datang dengan yang telah diramalkan (Husnan, 2014). Peramalan akan akurat jika melakukan minimisasi ketidakpastian yang mungkin terjadi dimasa yang akan datang.

Berbagai model telah dikembangkan di sektor industri maupun energi untuk peramalan dan untuk melihat ke dalam integrasi teknologi baru. Connolly et al. (2010) memberikan ulasan lebih dari 30 model yang berbeda yang dapat digunakan untuk menganalisis integrasi pendekatan sistem. Untuk lebih memaksimalkan kinerja peramalan, maka dilakukan kombinasi dengan sistem cerdas Agent Based Modelling (ABM) dengan sifatnya yang 
otonom berdasarkan lingkungan dari agen itu bekerja. Hal ini disebabkan sifat adaptf yang dimiliki agen (Xiang et al., 2005).

Untuk mengatasi masalah kesiapan permintaan suku cadang otomotif berbasis karet yang sering sulit mengantisipasi kekurangan maupun kelebihan stock, maka dilakukan peramalan permintaan dengan pendekatan ABM yang diintegrasikan dengan teknik peramalan Double Exponential Smoothing (DES). Penggunaan Agent Based Model ini memiliki keuntungan, yaitu melihat munculnya interaksi-interaksi dan perilaku agen (behaviour) yang terlibat di dalamnya dalam melakukan proses pemesanan suku cadang otomotif berbasis karet yang bersifat khusus dimana terlihat pihak yang satu memperoleh keuntungan atau kerugian dari pihak lainnya (simbiosis) (Bichraoui, 2013). Dengan simulasi yang direpresentasikan melalui class diagram dan state chart, maka dapat melihat perilaku dan interaksi masing-masing agen peramalan permintaan secara dinamis.

Integrasi DES dan ABM diperlukan supaya dapat memandu dalam melihat perkiraan akurasi peramalan, dapat memantau perkiraan kekurangan stock dan kelebihan stock akibat error pada peramalan DES, dengan cara merancang suatu model agen untuk peramalan permintaan suku cadang otomotif berbasis karet dengan Agent Based Modelling Double Exponential Smoothing (ABMDES). Oleh karena itu, tujuan penelitian ini adalah merancang model agen untuk peramalan permintaan suku cadang otomotif berbasis karet dengan pendekatan Agent Based Modelling and Double Exponential Smoothing (ABMDES).

\section{METODE PENELITIAN}

\section{Desain Model ABMDES}

Desain model pada peramalan suku cadang otomotif berbasis karet menggunakan integrasi ABM dan DES dilakukan dengan menggunakan pendekatan desain agen berbasis diagram kelas (class diagram) dan definisi behaviour (methods) untuk setiap agen dalam bentuk model matematika termasuk di dalamnya peramalan berbasis DES. Desain agen berbasis kelas memiliki struktur yang terdiri atas ID agen, atribut-atribut yang akan dilakukan proses perhitungan menggunakan komputer dan terakhir adalah behaviour/proses yang terdiri atas fungsi ataupun metode yang memiliki nilai dan void (tidak terstruktur). Struktur tersebut didefinisikan sebagai berikut (Gambar 1).

Selain itu, definisi interaksi antar agen dilakukan untuk mengetahui perilaku serta transfer data antar agen pada simulasi ABM menggunakan state chart/diagram (diagram status). Diagram status atau state diagram atau state chart diagram menunjukkan kondisi yang dapat dialami atau terjadi pada sebuah objek, sehingga setiap objek memiliki sebuah diagram status.

\begin{tabular}{|c|}
\hline ID \\
\hline Attributes \\
\hline Behaviour \\
\hline
\end{tabular}

Gambar 1. Struktur desain agen pada diagram kelas

\section{Use Case Diagram Sistem Peramalan Permintaan ABMDES}

Interaksi antara satu atau lebih aktor dengan sistem informasi yang akan dibuat digambarkan dengan Use Case (UC) diagram. UC digunakan untuk mengetahui fungsi apa saja yang ada di dalam sebuah sistem dan siapa saja yang berhak menggunakan fungsi-fungsi tersebut (Heriyanto, 2018). Interaksi antar aktor maupun antar UC pada diagram sistem peramalan permintaan ABMDES terdapat relasi dimana masing-masing memiliki perbedaan spesifikasi. Selanjutnya, sebuah aktor yang disebut aktor primer, bisa memiliki relasi inheritance dengan aktor yang lain. Gambar 2 mengilustrasikan sebuah UC diagram dengan aktor-aktor primer yaitu IKM, Manufaktur, dan Pasar.

Berdasarkan gambar rancangan use case (Gambar 2), maka alur program yang akan diterapkan menunjukkan aktor yang terlibat dalam sistem, yaitu IKM yang juga berperan sebagai retailer yang memiliki semua hak akses, baik ke pasar bebas maupun manufaktur. Pada UC antara IKM dan Manufaktur terdapat UC balancing supply demand on different timescales yang menunjukkan suatu upaya untuk menyeimbangkan antara pasokan dan permintaan. UC di bawahnya adalah kegiatan peramalan yang diperlukan untuk permintaan pasokan bahan baku suku cadang karet.

\section{Desain Objek Berbasis Diagram Kelas}

Agen pertama adalah pasar/user/industri otomotif yang membeli dan menggunakan suku cadang otomotif berbasis karet yang diproduksi dan dijual oleh IKM. Desain agen pasar adalah sebagai berikut (Gambar 3).

Diagram kelas juga menyediakan fitur pembangkitan kode untuk keperluan simulasi objek dan agent based berbasis Object Oriented Modelling dalam hal ini adalah Java. Masing-masing fungsi pada objek tersebut diformulasikan sebagai berikut:

$$
\begin{aligned}
& \text { generateOrder }= \\
& \operatorname{rand}(\min \text { value }(n, P, O), \text { max value }(n, P, O)) 4
\end{aligned}
$$

function ini berfungsi sebagai proses menghasilkan permintaan pada agen pasar/user/industri dengan nilai acak (random) dengan rentang nilai maksimum dan minimum untuk jenis produk $n$ dengan harga $P$ dan jumlah permintaan $O$.

$$
\text { sendOrder }=O_{n}^{\text {market } \rightarrow \text { retailer }}
$$




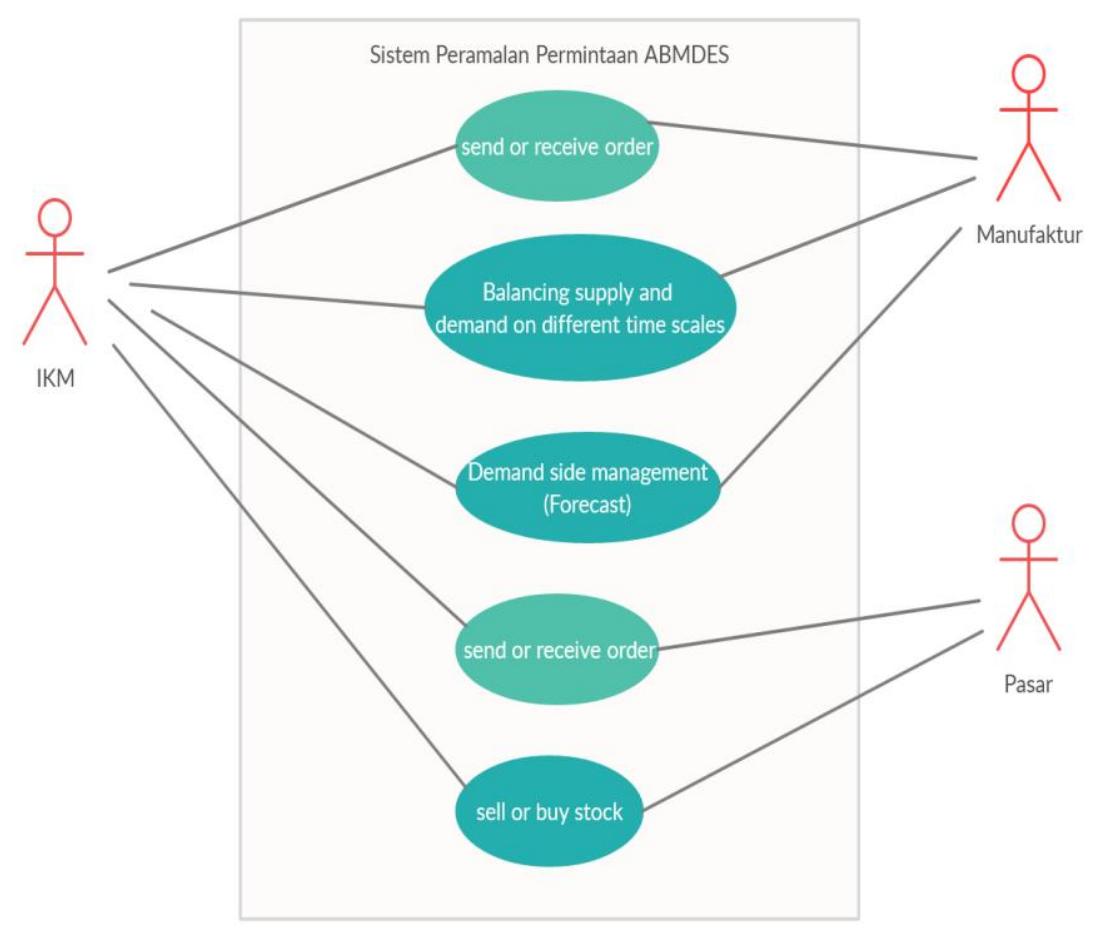

Gambar 2. Use case diagram usulan

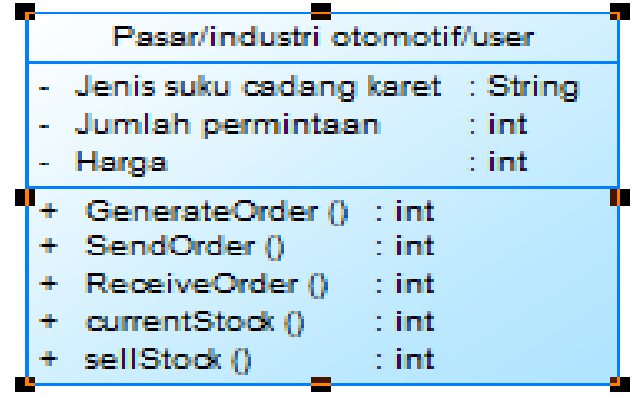

Gambar 3. Desain pasar/user/industri otomotif pada model peramalan

function sendOrder digunakan untuk melakukan proses pengiriman jumlah order $(O)$ kepada retailer untuk setiap jenis suku cadang otomotif berbasis karet $(n)$

$$
\text { receiveOrder }=S_{n}^{\text {retailer } \rightarrow \text { market }}
$$

function receiveOrder digunakan untuk menerima jumlah produk $(S)$ yang dikirim dari retailer dan market untuk spesifik produk suku cadang otomotif berbasis karet $(n)$

\section{currentStock $=I+$ receiveOrder}

function currentStock digunakan sebagai acuan stok yang ada di pasar yang dihitung dari inventori di pasar dijumlahkan dengan hasil return function dari currentStock.

Agen kedua adalah retailer, yang memiliki peran membeli suku cadang otomotif dari manufaktur dan menjual suku cadang kepada industri otomotif maupun market/user yang membutuhkan. Retailer pada penelitian ini memiliki peran sebagai aktor kunci pada peramalan permintaan dari pasar. Peramalan ini menentukan berapa jumlah produk yang akan dibeli oleh retailer untuk dijual ke pasar sehingga mendapatkan keuntungan kompetitif yang lebih baik. Desain agen retailer berbasis diagram kelas disajikan pada Gambar 4.

\begin{tabular}{|ll|}
\hline \multicolumn{2}{|c|}{ Retailer } \\
\hline - Jumlah pesanan dari pasar & : int \\
- Jumlah pengiriman & : int \\
- Jumlah pesanan ke manufaktur & : int \\
- Historis pesanan & : int \\
- Jumlah stok & : int \\
- Historis pengiriman/order & : int \\
\hline + DES 0 & : void \\
+ sendOrderToManufacture 0 & : int \\
+ receiveOrderFromManufacture 0 & : int \\
+ sendProductToMarket 0 & : int \\
+ receiveOrderFromMarket 0 & : int \\
+ actualSendOrderToMarket 0 & : int \\
+ GapActualVsForecasting 0 & : int \\
\hline
\end{tabular}

Gambar 4. Desain agen retailer

Beberapa fungsi yang didefinisikan pada model agen berbasis kelas untuk aktor retailer terdiri atas fungsi DES, sendOrderToManufacture, receiveOrderFromManufacture,

sendProductToMarket, actualSendOrderToMarket, gapActualVsForecasting. Fungsi DES didefinisikan sebagai berikut:

$$
\begin{array}{ll}
S_{t}=\alpha X_{t}+(1-\alpha)\left(S_{t-1}+b_{t-1}\right) & 0<\alpha<1 \\
b_{t-1}=\gamma\left(S_{t}-S_{t-1}\right)+(1-\gamma) b_{t-1} & 0<\alpha<1
\end{array}
$$


Peramalan dari pemulusan eksponensial linier diperoleh dengan menggunakan dua konstanta pemulusan, yaitu $\alpha$ (alfa) dan $\gamma$ (gama) dengan nilai antara 0 dan 1 (Makridakis, 1995). Dengan $S, b_{t}$ masing-masing merupakan pemulusan data dan pemulusan trend; $X$ menyatakan data aktual permintaan retailer dan $t$ merupakan periode dalam bulan dengan konstanta pemulusan $\alpha, \gamma$.

Function sendOrderToManufacture digunakan untuk melakukan pengiriman data pada simulasi ABM dari retailer kepada manufacturer untuk diproses dan dilakukan pengiriman pesanan suku cadang berbasis karet untuk spesifik produk $n$ tertentu. sendOrderToManufacture didefinisikan sebagai berikut:

sendOrderToManufacture $=$

$\operatorname{des}(n, P, O)^{\text {retailer } \rightarrow \text { manufacturer }}$

Function selanjutnya adalah receiveOrderFromManufacture yang digunakan untuk menerima aktual produk suku cadang otomotif berbasis karet dari manufacturer menuju retailer. Karena manufacturer pada ranti pasok produksi suku cadang sebelumnya diasumsikan mampu memenuhi order dari retailer maka nilai receiveOrderFromManufacture sama dengan nilai order yang dikirimkan dari retailer ke manufacturer atau function sendOrderToManufacture.

receiveOrderFromManufacture = sendOrderToManufacture

Function sendProductToMarket merupakan function yang digunakan untuk mengirim jumlah produk aktual yang dipesan market kepada retailer dengan nilai sama dengan receiveOrder pada agen market sehingga diformulasikan sebagai:

sendProductToMarket $=$ receiveOrder

Function receiveOrderFromMarket merupakan fungsi yang digunakan untuk menerima order yang datang dari market, sehingga nilai fungsi ini sama dengan generateOrder, sehingga diformulasikan sebagai berikut:

\section{receiveOrderFromMarket $=$ generateOrder}

Function actualSendOrderToMarket merupakan function yang digunakan untuk menerima kiriman produk suku cadang otomotif berbasis karet dari retailer menuju market, sehingga nilai dari function ini adalah sama dengan receiveOrder pada agen market, diformulasikan sebagai berikut:

\section{actualSendOrderToMarket $=$ receiveOrder}

Function gapActualVsForecasting digunakan untuk keperluan menghitung error peramalan yang didapat dari selisih antara actualSendOrderToMarket dengan sendOrderToManufacture sehingga diformulasikan sebagai:
gapActualVsForecasting $=$ | actualSendOrderToMarket - receiveOrder

Agen berikutnya adalah manufacturer atau rantai pasok sebelumnya yang memproduksi suku cadang otomotif berbasis karet. Agen manufacturer ini memiliki tugas pada sistem ABM sebagai penyuplai produk-produk suku cadang otomotif berbasis karet kepada retailer. Desain agen retailer berbasis kelas diagram adalah sebagai berikut (Gambar 5).

\begin{tabular}{|l|l|}
\hline \multicolumn{2}{|c|}{ Manufacturer } \\
\hline - totalProduksi $\quad$ : int \\
- totalOrderRetailer $\quad$ : int \\
- aktualSendProduct $\quad$ : int \\
\hline+ production () $\quad$ : void \\
+ actualSendtoRetailer () $\quad$ : int \\
\hline
\end{tabular}

Gambar 5. Diagram kelas untuk desain agen manufacturer

Function production digunakan untuk melakukan generate produksi yang akan dipasok untuk retailer. Nilai ini diasumsikan mampu memenuhi order yang datang dari retailer sejumlah $r$ sehingga formulasinya adalah sebagai berikut:

$$
\begin{aligned}
& \text { Production }(r) \\
& =\text { sendOrderToManufacture }(r)
\end{aligned}
$$

Function selanjutnya adalah actualSendtoRetailer diasumsikan juga sama dengan order yang diminta oleh retailer tertentu sehingga diformulasikan sebagai berikut:

actualSendtoRetailer $=$ sendOrderToRetailer

\section{HASIL DAN PEMBAHASAN}

\section{Desain State Diagram untuk Definisi Interaksi Antar Agen}

State chart diagram pada penelitian ini digunakan untuk mendesain bentuk interaksi antar aktor-aktor pada pemodelan berbasis agen. Berdasarkan diagram kelas dari masing-masing agen, maka dibuat desain pola interaksinya (Gambar 6) sebagai dasar untuk mendesain state chart diagram.

Interaksi antara pasar dan retailer adalah proses pembelian suku cadang dan melakukan peramalan untuk mengantisipasi permintaan yang datang dari market. Permintaan ini dilakukan ke industri, sehingga agen manufaktur melakukan generate produk sesuai pesanan dari retailer. Manufaktur melakukan pengiriman ke retailer yang selanjutnya dilakukan penyimpanan data pada state retailer. Market melakukan pesanan dan pesanan dikirimkan dari retailer ke market. 


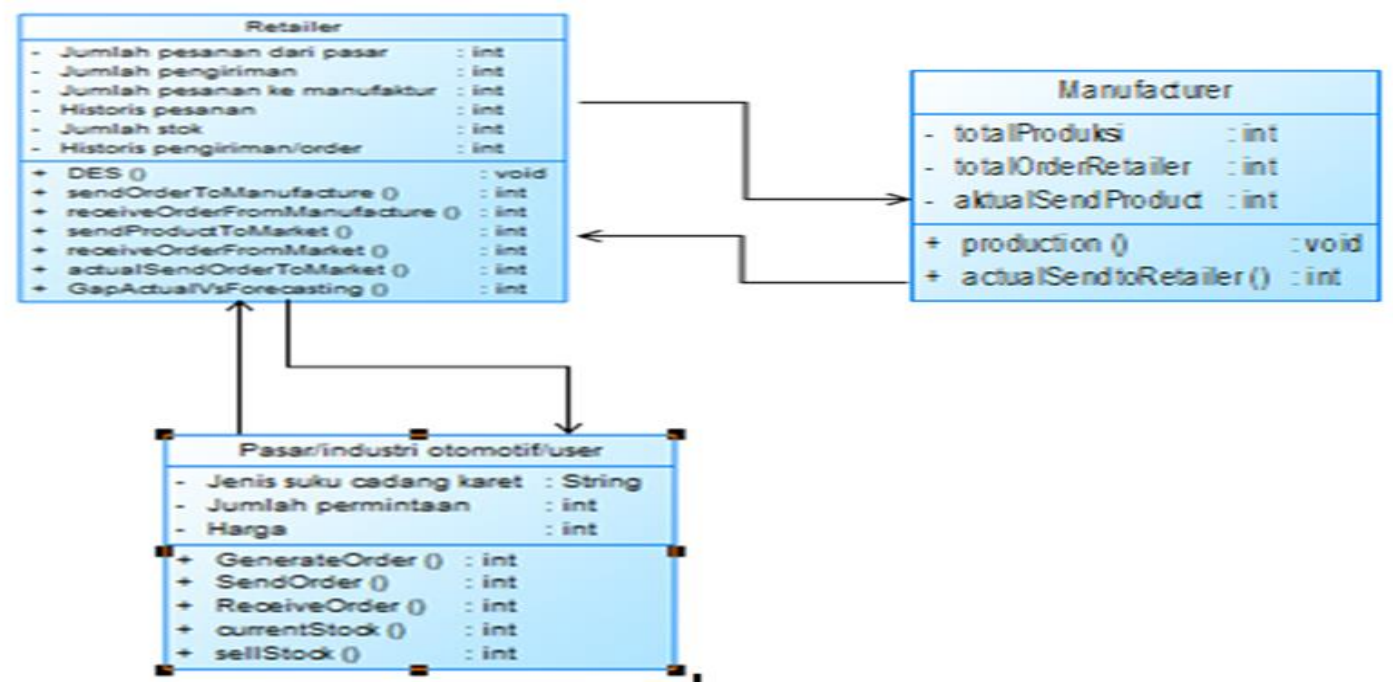

Gambar 6. Interaksi antar agen pada diagram kelas



Gambar 7. Desain state chart interaksi antar aktor pada proses pemesanan

Dari interaksi ini akan dapat dilakukan perhitungan keakuratan peramalan berbasis ABM. Jika akan dilakukan generate koding untuk keperluan simulasi ABM, maka perlu dibuat desain state chart interaksi antar aktor seperti pada Gambar 7.

\section{Analisis Hasil Peramalan Simulasi ABMDES}

Berdasarkan interaksi pada state chart ABMDES maka perlu dilakukan penelitian lanjutan untuk menghitung keakuratan peramalan berbasis $\mathrm{ABM}$ dan simulasi dengan menggunakan bantuan perangkat lunak NetBeans aplikasi Integrated Development Environment (IDE) versi 8.1 Professional / 2018 berbasiskan bahasa pemrograman Java dengan sistem operasi Windows, menggunakan function dan method Void yang cukup lengkap untuk simulasi. State-chart diagram dan desain agen berbasis diagram kelas sebelumnya sebagai input diolah dengan perangkat lunak NetBeans IDE 8.1 dengan bahasa pemrograman Java untuk dilakukan simulasi. Representasi simulasi model ABMDES ditunjukkan pada Gambar 8. 
ABMDES:

Input values: $[21.0,28.0,21.0,27.0,25.0,29.0,28.0,21.0,30.0,23.0,20.0,26.0,26.0,29.0,23.0]$ Smoothed values: [28.0, 28.279999999999998, 33.8912, 27.350848000000003, 30.78664192, Trend: $[7.0,5.88,5.8352,3.7726080000000004,3.7164723200000003,2.7906096128000004$, Level: $[21.0,22.4,28.056,23.57824,27.0701696,26.157328384,28.98958759936,28.7577054$ Forecast: [24.26887114814951, 24.23610479928545, 24.203338450421388, 24.17057210155] Sum of squared error ABMDES: $8.0 \%$

DES Value

Input values: $[21.0,28.0,21.0,27.0,25.0,29.0,28.0,21.0,30.0,23.0,20.0,26.0,26.0,29.0,23.0$, Forecast result $[24.5,24.5,24 \cdot 0,26.0,27.0,28.5,24.5,25 \cdot 5,26 \cdot 5,21 \cdot 5,23 \cdot 0,26 \cdot 0,27 \cdot 5,26 \cdot 0,23 \cdot 634435$ Sum of squared error DES: $8.0 \%$

Run/Re-run

Gambar 8. Representasi simulasi model ABMDES

Actual \& Forecasted Values

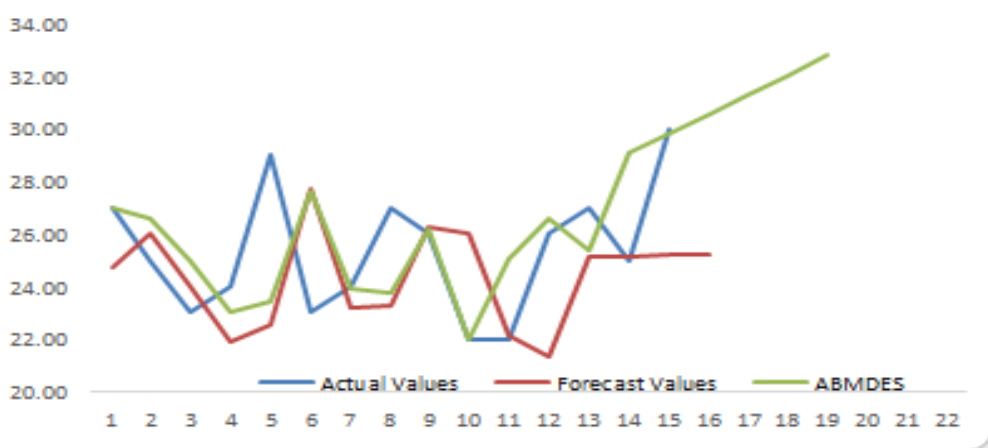

Gambar 9. Validasi Simulasi ABMDES $\alpha=0,8$ dan $\beta=0,2$

Setelah simulasi, verifikasi terhadap data hasil peramalan dilakukan. Perhitungan peramalan baru dilakukan dengan menggunakan spread sheet. Berdasarkan data hasil peramalan yang telah dihitung, maka dapat dilihat perbandingan data aktual dengan peramalan DES dan ABMDES sebagai berikut (Gambar 9).

Warna biru menunjukkan fluktuasi data actual, warna merah adalah hasil peramalan dengan DES, dan warna hijau adalah hasil peramalan dengan ABMDES. Dari hasil plot data menunjukkan adanya unsur trend yang menunjukkan data cenderung mengalami penurunan dalam kurun waktu yang cukup lama.

Langkah berikutnya adalah penentuan konstanta pemulusan $\alpha$ dan $\gamma$. Langkah tersebut dilakukan dengan bantuan komputer. Pada Gambar 9 menggunakan bobot konstanta $\alpha=0.8$ dan $\beta=0.2$, terlihat trend ABMDES lebih meningkat walaupun sama-sama mengalami pemulusan dan sangat fluktuatif. Hal ini jika disimulasikan dengan program Java untuk desain ABMDES dan Netbeans lebih terlihat jelas perbandingan error-nya antara DES dan ABMDES dimana ABMDES lebih kecil. Demikian juga setelah dilakukan repetisi masih ABMDES yang memiliki prosentase error terkecil.

\section{KESIMPULAN DAN SARAN}

\section{Kesimpulan}

Upaya meningkatkan permintaan (demand) bukan sekedar hasil perhitungan dari serangkaian keputusan pembelian dari konsumen tetapi sebaiknya sebagai hasil dari interaksi yang berulang. Kompleksitas dari sistem sangat penting untuk dipahami secara keseluruhan, tidak hanya proses penalaran terhadap setiap agen secara detail tetapi juga interaksi proses dinamisnya. Pada penelitian ini integrasi DES dengan ABM (ABMDES) dapat mengarahkan dengan lebih jelas peramalan permintaan sampai dengan memantau secara shortage kekurangan stok maupun kelebihan stok yang disebabkan error dari hasil peramalan. Oleh karena itu, pendekatan ABMDES sesuai untuk memodelkan permintaan suku cadang otomotif berbasis karet dalam simulasi bisnis.

\section{Saran}

Masih perlu dilakukan pengembangan modelmodel secara teknik yang mampu menangkap, menyimpan, menganalisis, mengelola, dan menghasilkan produk yang efisien dari segi biaya, jenis, kuantitas, dan mutu serta harga yang dapat 
bersaing, sehingga agroindustri karet Indonesia dapat bertahan dan lebih.

\section{DAFTAR PUSTAKA}

Adolph S, Cockburn A, dan Bramble P. 2002. Patterns for Effective Use Cases. Boston, USA: Addison-Wesley Longman Publishing Co, Inc.

Axelrod R. 1997. The dissemination of culture: a model with local convergence and global polarization. Journal Conflict Resolution: 41 (2) : 203-226.

Bichraoui N, Guillaume B, dan Halog. 2013. Agentbased modelling simulation for the development of an industrial symbiosis preliminary results. Procedia Environmental Sciences 17: 195-204.

Bonabeau E. 2002. Agent-based modeling: methods and techniques for simulating human systems. Proceedings National Academy Science. 99 (suppl 3): 7280-7287.

Cockburn A. 2000. Writing Effective Use Cases. 1st Edition. Boston, MA USA: Addison Wesley Longman Publishing Co.Inc.

Connolly T dan Carolyn B. 2010. Database Systems A Practical Approach To Design, Implementation, and Management. Fifth Edition. Boston: Pearson Education.

Giannakis M and Louis M. 2011. A multi-agent based framework for supply chain risk management. Journal Purchasing and Supply Management 17(1): 23-31.

Heriyanto Y. 2018. Perancangan sistem informasi rental mobil berbasis web pada PT APM Rent Car. Jurnal Intra-Tech 2(2): 64-77.

Husnan S dan Suwarsono M. 2014. Studi Kelayakan Proyek Bisnis. UPP STIM YKPN Yogyakarta.

Kurniawan TA. 2018. Pemodelan use case (UML): evaluasi terhadap beberapa kesalahan dalam praktik. Jurnal Teknologi Informatika dan Ilmu Komputer. 5(1): 77-86.

Kwon O, Im GP, dan Lee KC. 2011. An agent-based web service approach for supply chain collaboration. Scientia Iranica 18(6): 15451552.

Lazim A. 2011. Introductory business forecasting: A practical approach (3rd Ed.). University Publication Centre (UPENA), UiTM 2005, 2007, 2011.

Li dan Chan FTS. 2013. An agen-based model of supply chains with dynamic structures. Applied Mathematical Modelling 37(7): 5403-5413.

Lianny I, Fatmawati T, dan Ismono A. 2015. Analisis dan perancangan sistem informasi manufaktur industri kecil dan menengah (IKM) komponen otomotif. Jurnal Teknologi dan Manajemen 13(1).55-62.

Makridakis S, Wheelwright C, dan McGee VE. 1995. Metode dan Aplikasi Peramalan Jakarta: Penerbit Erlangga.

Nikiforova O, Sejans J, dan Cernickins A. 2011. Role of $U M L$ class diagram in object-oriented software development. Scientific Journal Riga Technical University Computer Sciences 44(1): 65-74.

Parunak HVD, Savit R, dan Riolo RL. 1998. Agentbased modeling vs. equation-based modeling: A case study and users guide. In: Multi-Agent Systems and Agent-Based Simulation. Springer, 10-25.

Sumayang L. 2003. Dasar-Dasar Manajemen Produksi dan Operasi. Jakarta: Salemba Empat.

Wu L, Liu S, dan Yang Y. 2016. Grey double exponential smoothing model and its application on pig price forecasting in China. Applied Soft Computing. 39 : 117-123.

Xiang X, Kennedy RC, dan Maddey G. 2005. Cabaniss verification and validation of agentbased scientific simulation models. Department of Computer Science and Engineering University of Notre Dame IN46556 